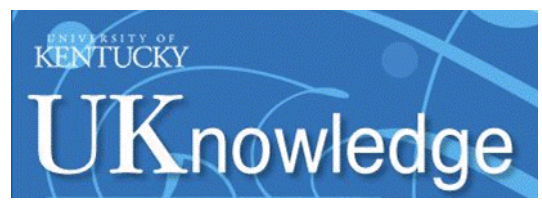

University of Kentucky

UKnowledge

\title{
Role of Protein Charge Density on Hepatitis B Virus Capsid Formation
}

Xinyu Sun

The University of Akron

Dong Li

Lawrence Berkeley National Laboratory

Zhaoshuai Wang

University of Kentucky, zhaoshuai.wang@uky.edu

Panchao Yin

South China University of Technology, China

Rundong $\mathrm{Hu}$

The University of Akron

See next page for additional authors

Follow this and additional works at: https://uknowledge.uky.edu/chemistry_facpub

Part of the Amino Acids, Peptides, and Proteins Commons, Molecular Biology Commons, and the Viruses Commons

Right click to open a feedback form in a new tab to let us know how this document benefits you.

\section{Repository Citation}

Sun, Xinyu; Li, Dong; Wang, Zhaoshuai; Yin, Panchao; Hu, Rundong; Hu, Rundong; Li, Hui; Liu, Qiao; Gao, Yunyi; Ren, Baiping; Zheng, Jie; Wei, Yinan; and Liu, Tianbo, "Role of Protein Charge Density on Hepatitis B Virus Capsid Formation" (2018). Chemistry Faculty Publications. 123.

https://uknowledge.uky.edu/chemistry_facpub/123

This Article is brought to you for free and open access by the Chemistry at UKnowledge. It has been accepted for inclusion in Chemistry Faculty Publications by an authorized administrator of UKnowledge. For more information, please contact UKnowledge@lsv.uky.edu. 


\section{Role of Protein Charge Density on Hepatitis B Virus Capsid Formation}

Digital Object Identifier (DOI)

https://doi.org/10.1021/acsomega.8b00021

\section{Notes/Citation Information}

Published in ACS Omega, v. 3, issue 4, 4384-4391.

Copyright $\odot 2018$ American Chemical Society

This is an open access article published under an ACS AuthorChoice License, which permits copying and redistribution of the article or any adaptations for non-commercial purposes.

Authors

Xinyu Sun, Dong Li, Zhaoshuai Wang, Panchao Yin, Rundong Hu, Rundong Hu, Hui Li, Qiao Liu, Yunyi Gao, Baiping Ren, Jie Zheng, Yinan Wei, and Tianbo Liu 


\title{
Role of Protein Charge Density on Hepatitis B Virus Capsid Formation
}

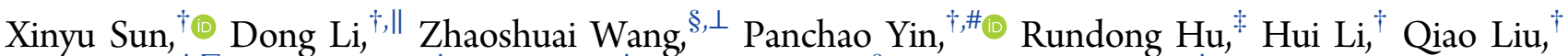

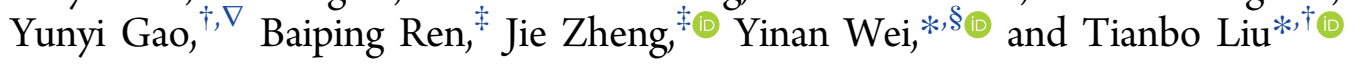

${ }^{\dagger}$ Department of Polymer Science and Department of Chemical and Biomolecular Engineering, The University of Akron, Akron, Ohio 44325, United States

${ }^{\S}$ Department of Chemistry, University of Kentucky, Lexington, Kentucky 40506, United States

\section{Supporting Information}

ABSTRACT: The role of electrostatic interactions in the viral capsid assembly process was studied by comparing the assembly process of a truncated hepatitis $\mathrm{B}$ virus capsid protein Cp149 with its mutant protein D2N/D4N, which has the same conformational structure but four fewer charges per dimer. The capsid protein self-assembly was investigated under a wide range of protein surface charge densities by changing the protein concentration, buffer $\mathrm{pH}$, and solution ionic strength. Lowering the protein charge density favored the
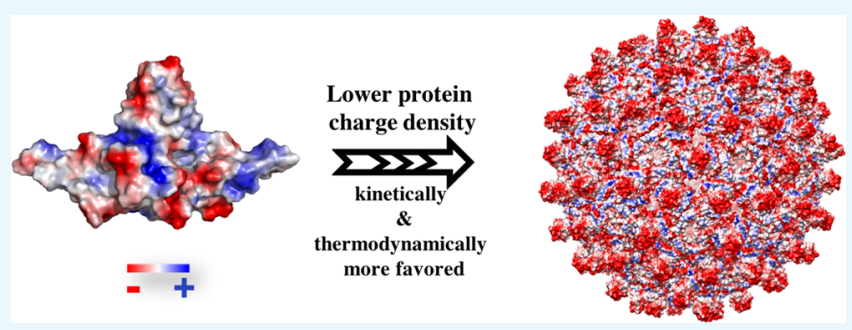
capsid formation. However, lowering charge beyond a certain point resulted in capsid aggregation and precipitation. Interestingly, both the wild-type and D2N/D4N mutant displayed identical assembly profiles when their charge densities matched each other. These results indicated that the charge density was optimized by nature to ensure an efficient and effective capsid proliferation under the physiological $\mathrm{pH}$ and ionic strength.

\section{INTRODUCTION}

Viral capsids are symmetric protein shells made up of copies of one or a few different types of capsid proteins (Cps). Besides their basic function of protecting the viral genome enclosed inside, they also play a role in many steps of the infection cycle, including genome replication, assembly of progeny viruses and disassembly for genome release. ${ }^{1-3}$ To be viable, virus capsids exhibit efficient assembly with high fidelity, sufficient stability against inactivation, and at the same time, certain fragility to release genetic content upon infection. ${ }^{4-6}$ Noncovalent interactions between capsid proteins play a key role in this process. Studying the nature of noncovalent interactions between these biomacromolecules can help to understand and even predict the behavior of capsids, thus further promoting the development of new antiviral strategies. ${ }^{7-13}$

In this study, hepatitis B virus (HBV) was chosen as the model to explore how the electrostatic interactions between protein-protein and protein-counterion could affect the capsid assembly. HBV is a liver tissue specific enveloped DNA virus, which is also a causative factor for the development of hepatocellular carcinoma and liver cirrhosis. It has been used as a common model system for understanding the viral capsid assembly and virus-host interactions. The HBV core protein has a full length of 183 amino acids with its C-terminal tail (residues 150-183) responsible for nucleic acid binding. When the last 34 residues are truncated, the remaining polypeptide with 149 residues (Cp149) is still able to assemble into capsids when different salts are introduced. ${ }^{14-17}$ The assemblies exhibit similar morphology and antigenic properties as the native capsids isolated from cell cultures and still present the coexistence of $T=3$ and $T=4$ (predominant) structures. $^{15}$ Thus, $\mathrm{Cp}-\mathrm{Cp}$ interactions alone are capable of driving capsid formation, and the negatively charged Cp149 is a good candidate to investigate the role of electrostatic interactions during capsid formation. Dimer $\mathrm{Cp} 149_{2}$ is the basic building unit of the capsids. In vitro capsid assembly of HBV Cp149, had been studied under different $\mathrm{pHs}$, protein concentrations, and salt concentrations. ${ }^{18-20}$ Extensive experiments, including $\mathrm{Cp}$ mutations, have been conducted to emphasize the importance of the hydrophobic interaction as a driving force for assembly. ${ }^{21,22}$ However, the research on the role of electrostatic interactions in empty capsid assembly was limited to theoretical calculations. ${ }^{23,24}$ Unlike many noncovalent interactions that become effective only at a short distance, electrostatic interactions are unique long-range forces. As a result, they play pivotal roles in many important biological processes. It is important to experimentally explore their contribution to the overall capsid formation and capsid stability, so as to generate a comprehensive understanding of the major interactions in capsid assembly and further apply this knowledge to comprehend the capsid behavior in general.

Toward this goal, two aspartic acids (D) were replaced with neutral asparagines $(\mathrm{N})$ to create a mutant Cp149 dimer D2N/ $\mathrm{D} 4 \mathrm{~N}$ to remove two negative charges from each wild-type

Received: January 3, 2018

Accepted: April 11, 2018

Published: April 20, 2018 


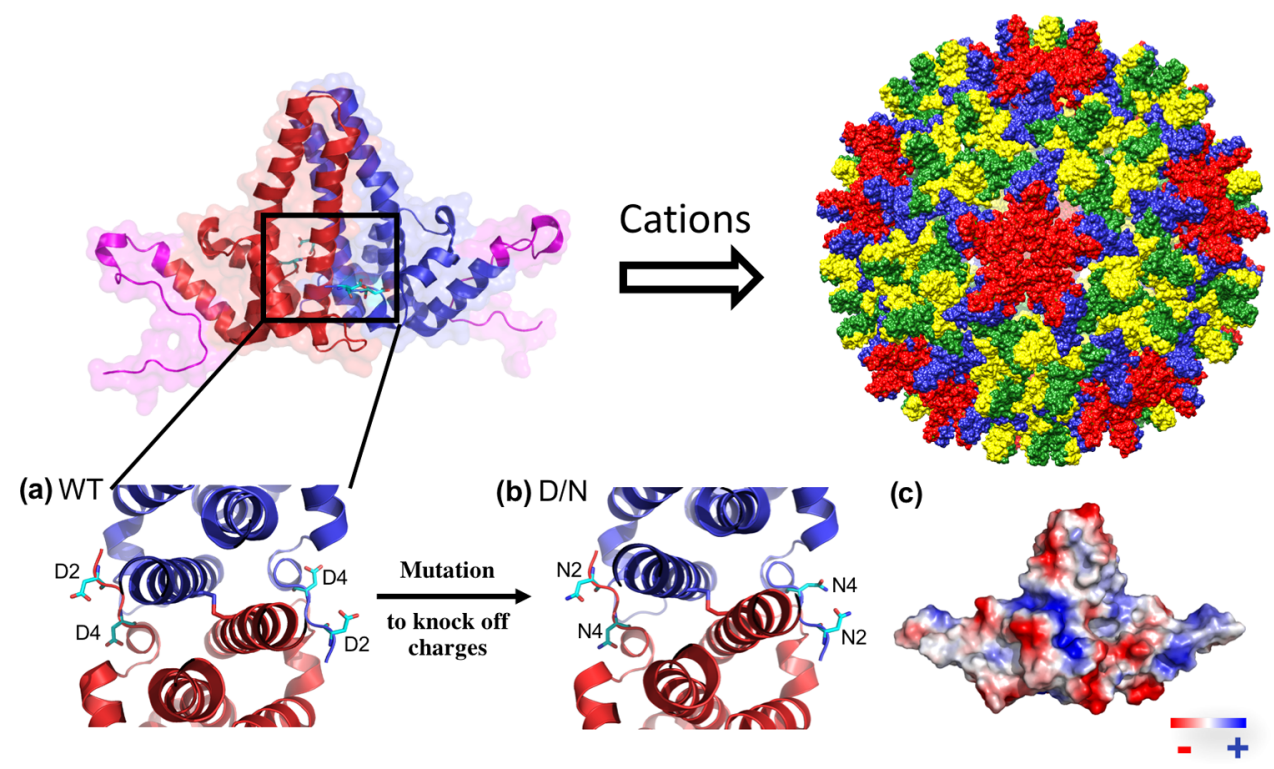

Figure 1. Graphic illustration of HBV Cp149 dimer and its capsid formation. A WT Cp149 dimer ((a) viewed from the top) consists of two identical subunits (red and blue). The edge of the dimer (magenta) dominates the dimer-dimer interactions when dimers are associated into capsids. ${ }^{25} \mathrm{~A} T=$ 4 capsid is shown, with its subunits in four quasi-equivalent conformations colored by red, blue, yellow, and green. A mutant ((b) D2N/D4N) was created by replacing the 2nd and 4th Asp with neutral Asn (shown as sticks) to reduce the overall charge density on a dimer. (c) Molecular surface of a dimer colored according to electrostatic potential (red and blue represent negative and positive, respectively).

Table 1. Net Charge of WT and Mutant D2N/D4N Dimers at Different pHs

\begin{tabular}{lccccccccc}
\multicolumn{1}{c}{ charge number } & $\mathrm{pH}=6.60$ & $\mathrm{pH}=7.00$ & $\mathrm{pH}=7.50$ & $\mathrm{pH}=8.00$ & $\mathrm{pH}=8.50$ & $\mathrm{pH}=8.77$ & $\mathrm{pH}=9.20$ & $\mathrm{pH}=9.60$ \\
WT dimer & -10.4 & -12.4 & -14.4 & -16.4 & -18.8 & -20.4 & -22.8 & -25.6 \\
D2N/D4N dimer & -6.4 & -8.4 & -10.4 & -12.4 & -14.8 & -16.4 & -18.8 & -21.6 \\
\hline
\end{tabular}

(WT) protein monomer (Figure 1a,b). The mutation sites were selected at the very beginning of N-terminus to avoid the potential effect on dimer association or protein folding. Thus, the observed difference in the assembly behavior could be attributed to macroion-counterion interactions. The assembly kinetics and thermodynamics of WT and D2N/D4N were investigated under different conditions. It was found that Cp149 dimers were highly soluble and remained stable in solution because of their surface charges. The incorporation of additional counterions screened the surface charges and triggered dimer association into capsids. A lower protein surface charge density favored capsid assembly, which explained the faster and more stable formation of capsids at lower $\mathrm{pH}$ values. It was also discovered that the charge density of a protein was more important when the salt concentration in the buffer was low. Furthermore, it appeared that the charge number of the WT capsid protein enabled an efficient and effective capsid proliferation, suggesting that the charge number has been evolutionarily optimized.

\section{RESULTS AND DISCUSSION}

2.1. Monitoring and Characterization of WT Capsid Formation. Each WT Cp149 dimer carries about 14 negative charges at $\mathrm{pH} 7.5$ (Table 1 and Supporting Information for calculation and measurement details). Potassium ions $\left(\mathrm{K}^{+}\right)$ were chosen as the counterions to study the capsid formation due to their abundance in human cells where HBV replication takes place. Prior to the addition of $\mathrm{KCl}$ salt, Cp149 proteins remained as homodimers in solution, as shown by an average hydrodynamic radius $\left(R_{\mathrm{h}}\right)$ of $3.5 \mathrm{~nm}$ from the dynamic light scattering (DLS) measurements (Figure 2a). Static light scattering (SLS) was used to monitor the assembly process. As shown in Figure $2 \mathrm{c}$, once $0.2 \mathrm{M} \mathrm{KCl}$ was added to the WT protein solution (e.g., $2.0 \mathrm{mg} \mathrm{mL} \mathrm{m}^{-1}$ ), the scattered light intensity immediately started to rapidly increase for the first 10 min, then the growth became slower. Capsid assembly reached equilibrium within $24 \mathrm{~h}$. Because the scattered light intensity $I$ $\propto C \times M_{\mathrm{W}},{ }^{26}$ with $C$ and $M_{\mathrm{W}}$ being the mass concentration and the molecular weight of the solutes, respectively, small dimer proteins scatter light much less than large capsids (120 times of the dimer's mass). Therefore, the increase of the scattered intensity with time reflects the kinetics of capsid formation. The intensity stopped growing when dimers and capsids reached equilibrium. Higher protein concentration and salt concentration both accelerated the assembly rate and increased the final capsid concentration, as shown by a steeper slope of the intensity increment curve and a higher final intensity (Figures $2 \mathrm{c}-\mathrm{e}$ and $4 \mathrm{~b}$ ). During the capsid assembly, the $R_{\mathrm{h}}$ peak of dimers gradually reduced, whereas a new capsid peak appeared (Figure 2a). Because Cp149 dimers can form $T=3(R=16$ $\mathrm{nm})$ and $T=4$ capsids $(R=18 \mathrm{~nm})$ in solution, the measured $R_{\mathrm{h}}$ of $18.3 \pm 0.5 \mathrm{~nm}$ is consistent with the average size of mixed capsids, with $T=4$ being the dominant species. ${ }^{27} T=3$ and $T$ $=4$ capsids could not be distinguished through the DLS technique, but the existence of both was verified using transmission electron microscope (TEM) imaging of negatively stained samples (Figure 3a).

2.2. Lower Protein Charge Density Favors Capsid Assembly. Scattered light intensity monitored by SLS revealed that $\mathrm{D} 2 \mathrm{~N} / \mathrm{D} 4 \mathrm{~N}$ dimers assembled much faster and reached a higher final scattering intensity than WT Cp149 dimers (Figure $2 \mathrm{c}, \mathrm{d})$. A capsid radius of $R_{\mathrm{h}}=17.5 \pm 0.4 \mathrm{~nm}$, similar to that of 
a)

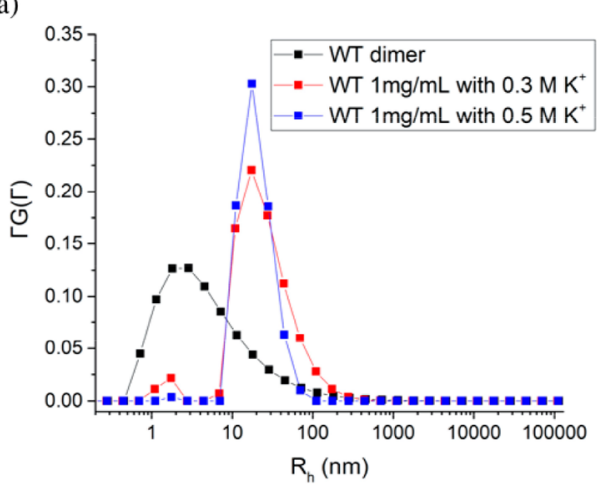

b)

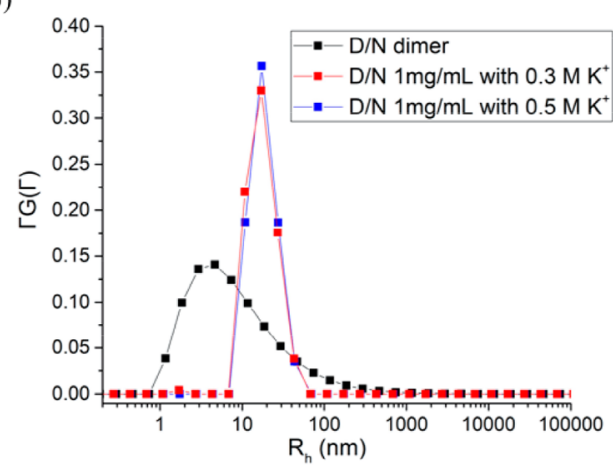

e)
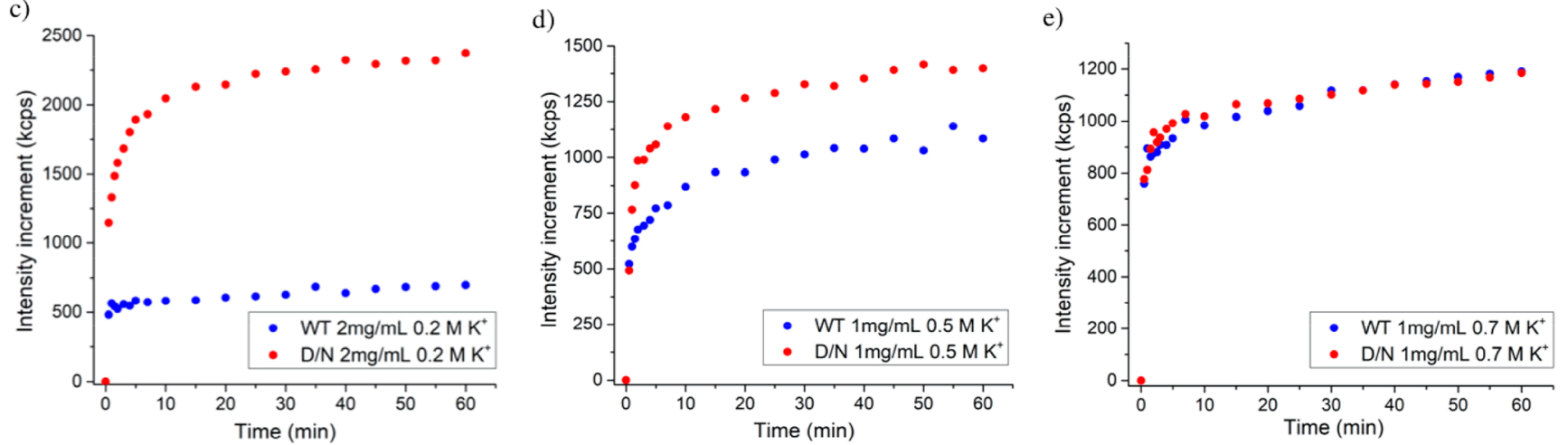

Figure 2. DLS and time-resolved SLS monitoring results of protein assembly at $\mathrm{pH} 7.5$ ((4-(2-hydroxyethyl)-1-piperazineethanesulfonic acid) (HEPES) buffer). (a, b) CONTIN analysis of DLS studies reflected the growth of capsid from WT (a) and D2N/D4N (b) dimers with the addition of $\mathrm{K}^{+}$. The $y$-axis $\Gamma G(\Gamma)$ denotes the relative contribution to the total scattered intensity due to the particles with a given $R_{\mathrm{h}} ;(\mathrm{c}-\mathrm{e})$ time-resolved intensity increment of $\mathrm{WT}$ and $\mathrm{D} 2 \mathrm{~N} / \mathrm{D} 4 \mathrm{~N}$ capsid formation with a single aliquot addition of $\mathrm{K}^{+}$to reach $0.2 \mathrm{M}$ (protein concentration $2.0 \mathrm{mg}$ $\mathrm{mL}^{-1}$ ), 0.5 M (protein concentration $1.0 \mathrm{mg} \mathrm{mL}^{-1}$ ), and $0.7 \mathrm{M}$ (protein concentration $1.0 \mathrm{mg} \mathrm{mL}^{-1}$ ) at $\mathrm{pH} 7.5$.
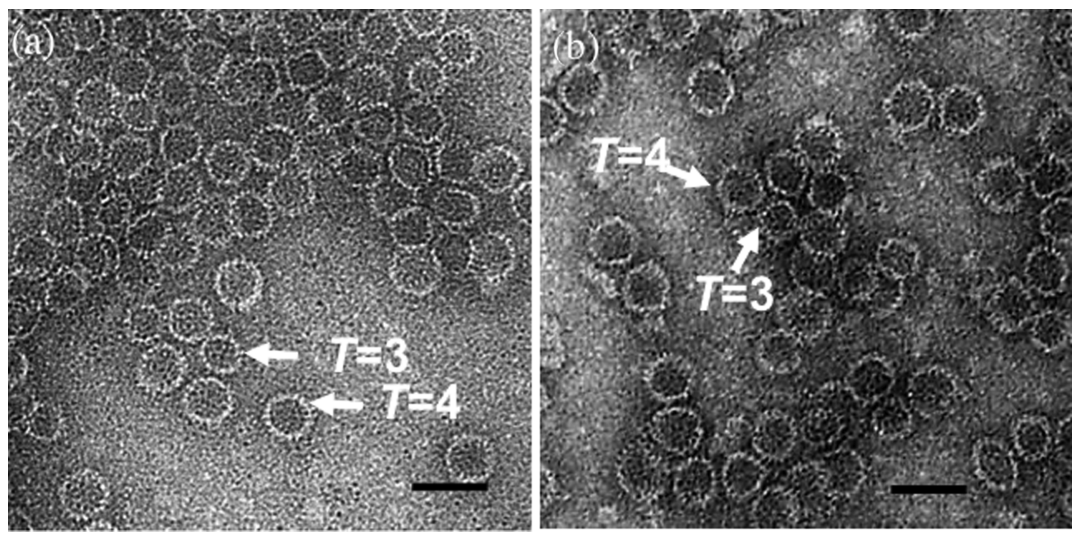

Figure 3. TEM images of WT capsids (a) and D2N/D4N capsids (b) assembled at $\mathrm{pH} 7.5$ with HEPES buffer containing $1.0 \mathrm{M} \mathrm{KCl}$ at room temperature. Scale bar is $50 \mathrm{~nm}$.

WT, was obtained from the DLS studies (Figure 2b). The same capsid morphology and a combination of $T=3$ and $T=4$ structures were verified on TEM images (Figure $3 \mathrm{~b}$ ). Therefore, the higher scattering intensity indicated that more capsids were formed from D2N/D4N dimers under the same condition. This difference in the capsid formation was mainly due to different dimer charge densities. The impact from mutation was excluded because the overall structures of WT and D2N/D4N mutants were the same, demonstrated by their overlapped circular dichroism (CD) and fluorescence spectra in Figure S1D,E, and the mutated sites were not involved in dimer-dimer association (Figure S1). The lower charge density of $\mathrm{D} 2 \mathrm{~N} / \mathrm{D} 4 \mathrm{~N}$ dimers resulted in weaker electrostatic repulsion between dimers, which promoted the capsid formation and more capsids were formed under the same condition. Furthermore, $\mathrm{CD}$ and fluorescence spectra indicated that the addition of $\mathrm{KCl}$ did not lead to detectable secondary or tertiary structural change (Figure S2), confirming that the association of monovalent salts with protein was playing a charge screening role without changing the protein conformation.

HBV Cp149 dimers are highly soluble and can be regarded as macroions in aqueous solution, although they have hydrophobic patches on the surface. When dimers self-assemble into capsids, $75 \%$ of the buried contact surface is hydrophobic, contributed from more than $50 \%$ of the hydrophobic residues in the contact region (Figure 1). The hydrophobic contact area 


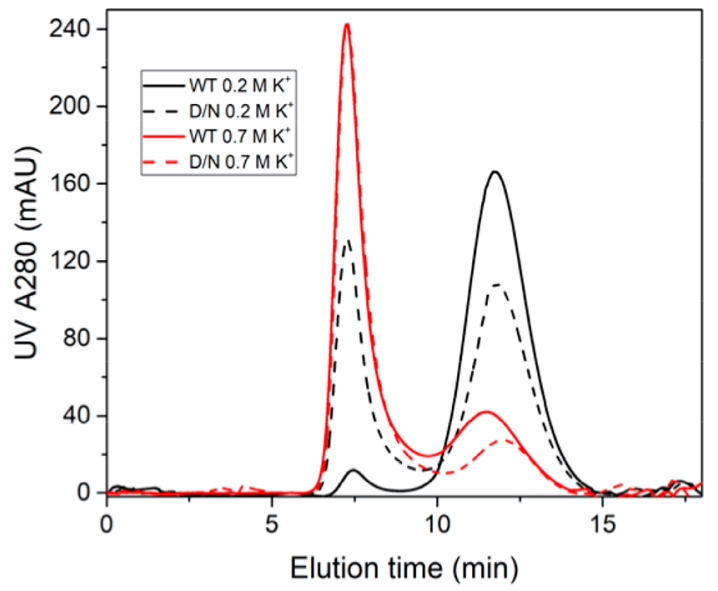

b)

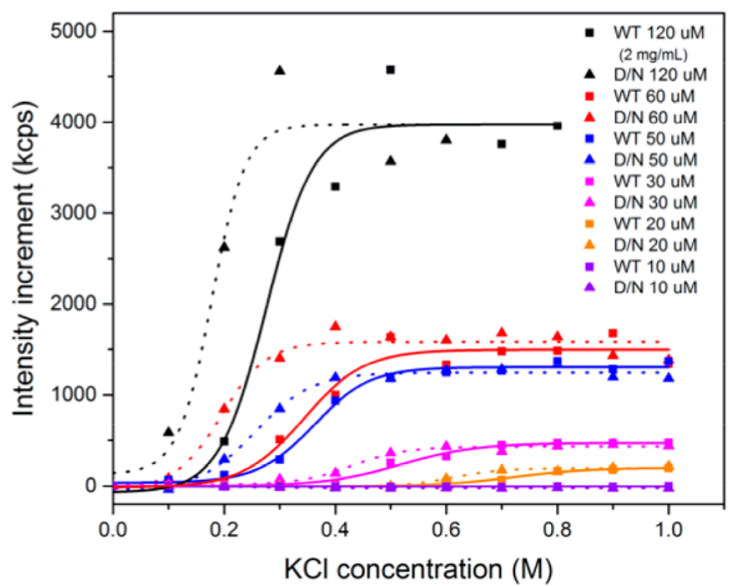

Figure 4. Thermodynamic differences between WT and mutant dimers incubated with low salt and high salt concentrations. (a) Size exclusion chromatography (SEC) analysis of Cp149 2 capsid assembly for $1.0 \mathrm{mg} \mathrm{mL}^{-1} \mathrm{WT}$ and $1.0 \mathrm{mg} \mathrm{mL}^{-1} \mathrm{D} 2 \mathrm{~N} / \mathrm{D} 4 \mathrm{~N}$ protein solutions in low salt (0.2 M $\mathrm{KCl})$ or high salt $(0.7 \mathrm{M} \mathrm{KCl}) \mathrm{pH} 7.5$ buffer. Capsids elute at $7.5 \mathrm{~min}$ and dimers at $11.7 \mathrm{~min}$. (b) Final scattered intensity increment of WT and D2N/D4N capsid assemblies as a function of $\mathrm{KCl}$ concentration in $\mathrm{pH} 7.5 \mathrm{HEPES}$ buffer after reaching equilibrium.

is $~ 5.5-7.6 \mathrm{~nm}^{2}$ and is not affected by the mutation. ${ }^{19}$ Therefore, the hydrophobic interaction should be the same for both the WT and D2N/D4N. This short-range attraction was balanced by long-range electrostatic repulsion, which regulated the Cp $149_{2}$ assembly. In the WT protein sequence, there are 17 basic residues and 14 acidic ones, resulting in an isoelectric point at $\mathrm{pH} 5.05$. At $\mathrm{pH} 7.5$, the effective surface charge density of the WT dimer was -0.40 charges $\mathrm{nm}^{-2}$ (dimer surface area is $\sim 36.3 \mathrm{~nm}^{2}$ ), whereas that of $\mathrm{D} 2 \mathrm{~N} / \mathrm{D} 4 \mathrm{~N}$ was lowered to -0.29 charges $\mathrm{nm}^{-2}$. The presence of additional $\mathrm{K}^{+}$ions further screened the negative charges and lowered the effective charge density. The reduced protein-protein repulsion made the hydrophobic attraction more dominant and the capsid formation more favored.

2.3. Capsid Formation is Sensitive to Surface Charge Density at Certain Salt Concentrations. The ionic strength in solution is critical to the solution behavior of proteins. When the salt concentration was too low, the repulsive proteinprotein interactions dominated over the hydrophobic attraction among them; thus, capsids were barely formed. Increasing $\mathrm{K}^{+}$ concentration to $0.2 \mathrm{M}$ enabled rapid association of D2N/D4N dimers, especially at higher protein concentrations (Figure 2c). After reaching equilibrium, the $1.0 \mathrm{mg} \mathrm{mL}^{-1} \mathrm{D} 2 \mathrm{~N} / \mathrm{D} 4 \mathrm{~N}-0.2 \mathrm{M}$ $\mathrm{K}^{+}$solution had $44 \%$ of dimer proteins assembled into capsids, as determined by the elution peak area ratio of capsids over the total contribution from proteins, obtained from size exclusion chromatography (SEC). At the same salt concentration, much fewer capsids were formed in WT protein solutions due to a higher charge density (Figure $4 \mathrm{a}$ ). When $\mathrm{K}^{+}$was increased to $0.5 \mathrm{M}$, the difference between $\mathrm{WT}$ and $\mathrm{D} 2 \mathrm{~N} / \mathrm{D} 4 \mathrm{~N}$ capsid formation still existed but became smaller (Figure 2d). Capsid formation was further diminished when more $\mathrm{K}^{+}$was added (Figure 2e). When $0.7 \mathrm{M} \mathrm{K}^{+}$was added, the portions of $\mathrm{Cp} 149_{2}$ $\left(1.0 \mathrm{mg} \mathrm{mL}^{-1}\right.$ ) assembled into capsids at equilibrium are $87 \%$ (WT) and $89 \%(\mathrm{D} 2 \mathrm{~N} / \mathrm{D} 4 \mathrm{~N})$ (Figure 4a). In terms of association energy per contact, ${ }^{19}$ the $\Delta G_{\text {contact }}$ was calculated as -3.01 and $-3.18 \mathrm{kcal} \mathrm{mol}^{-1}$ for WT and D2N/D4N at the low salt concentration $(0.2 \mathrm{M} \mathrm{KCl})$, respectively. Under the high salt condition $(0.7 \mathrm{M} \mathrm{KCl})$, however, the $\Delta G_{\text {contact }}$ of WT and $\mathrm{D} 2 \mathrm{~N} / \mathrm{D} 4 \mathrm{~N}$ assembly became much closer by $53 \%$, being -3.56 and $-3.65 \mathrm{kcal} \mathrm{mol}^{-1}$, respectively (calculation details in the Supporting Information). These results indicated that excessive amount of counterions led to a strong proteincounterion binding that could diminish the charge density difference between proteins, resulting in a similar assembly behavior kinetically and thermodynamically. In contrast, at lower salt concentration, e.g., $0.2 \mathrm{M} \mathrm{K}^{+}$, which is close to the ionic strength in the cell, the kinetics and thermodynamics of the capsid formation were strongly affected by the protein charge density.

A series of experiments with varying protein concentrations were conducted to further explore the effective salt range where protein charge played roles. As shown in Figure $4 \mathrm{~b}, \mathrm{KCl}$ was titrated into protein solutions at various concentrations with an increment of $0.1 \mathrm{M}$ per $24 \mathrm{~h}$ to a final concentration of $1.0 \mathrm{M}$. On-line scattered intensities in SLS were recorded to monitor capsid formation. Obviously, higher protein concentrations favored the capsid formation, represented by the higher scattered intensity and a lower critical salt concentration (CSC). The CSC of D2N/D4N solution increased from $<0.1$ to $0.6 \mathrm{M}$ of $\mathrm{K}^{+}$when protein concentration dropped from 120 to $20 \mu \mathrm{M}$. The CSC of D2N/D4N was always slightly lower than that of WT. Interestingly, proteins with different charge densities had their own assembly-sensitive counterion concentration regions, shifting to higher $\left[\mathrm{K}^{+}\right]$when lowering $\left[\mathrm{Cp} 149_{2}\right]$ (Figure $4 \mathrm{~b}$ ). Above this $\left[\mathrm{K}^{+}\right]$region is where the final scattered intensities for D2N/D4N and WT reached the same plateau, indicating that most dimers had formed into capsids. The effect of charge difference on capsid formation was screened by excess counterions. Within this $\left[\mathrm{K}^{+}\right]$region, D2N/ $\mathrm{D} 4 \mathrm{~N}$ formed more capsids than WT. The screening effect-regulated assembly was very sensitive to protein charge and the variation of ionic strength, and the absence of four negative charges made a significant difference in capsid assembly. Below this $\left[\mathrm{K}^{+}\right]$range, few capsids formed.

Although only $\mathrm{K}^{+}$was used for capsid assembly in this work, various salts and salts of different valances have been explored by Zlotnick and other groups ${ }^{16,17}$ As previously reported, $\mathrm{Na}^{+}$ and $\mathrm{K}^{+}$induced $\mathrm{Cp} 149_{2}$ assembly with similar critical concentrations, whereas divalent ions, such as $\mathrm{Mg}^{2+}$ and $\mathrm{Ca}^{2+}$, significantly promoted the assembly with a 4 times lower critical concentration. Interestingly, the effect of counterions on 
a)

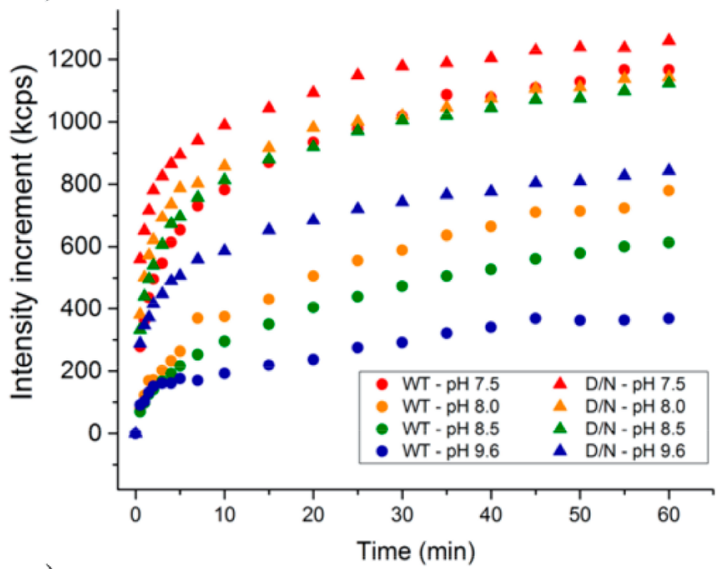

c)

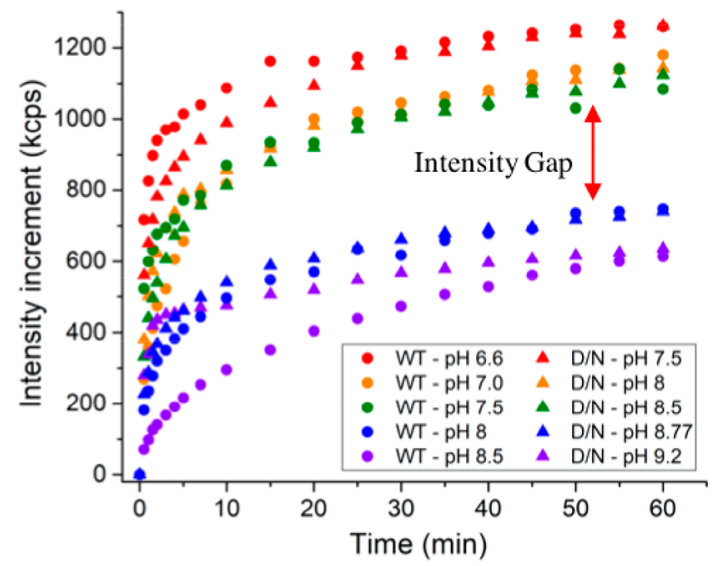

b)

d)
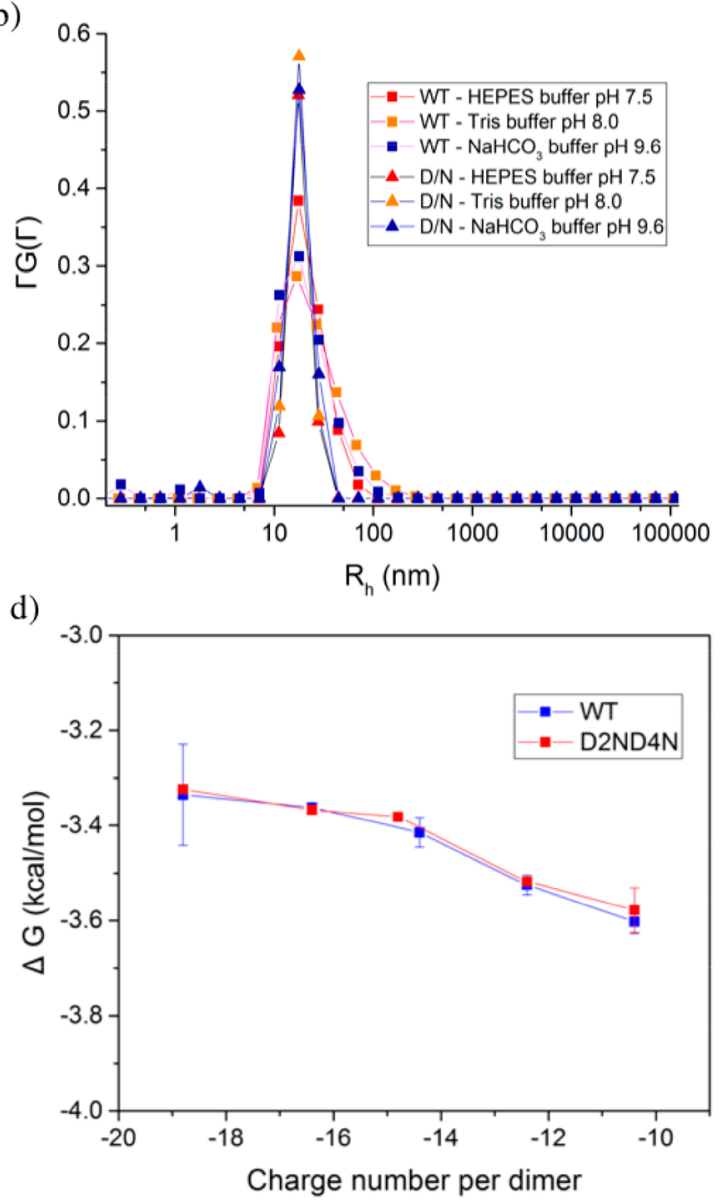

Figure 5. Kinetic and thermodynamic studies of $\mathrm{Cp} 149_{2}$ assembly with various protein charges. (a) Effect of $\mathrm{pH}$ (charge) on assembly kinetics of WT and $\mathrm{D} 2 \mathrm{~N} / \mathrm{D} 4 \mathrm{~N}$ proteins (Tris buffer covers $\mathrm{pH} 7.5-8.5 ; \mathrm{NaHCO}_{3}$ buffer used at $\mathrm{pH}$ 9.6). The assembly rate slowed down with an increasing $\mathrm{pH}$. The assembly of the mutant was always faster than the WT when compared at the same $\mathrm{pH}$; (b) CONTIN results from DLS studies showed the same $R_{\mathrm{h}}$ distribution of WT and mutant capsids over a wide range of $\mathrm{pH} ;(\mathrm{c})$ proteins carrying the same charge numbers (represented by the same color) showed the similar assembly kinetics pathways. The assemblies in this plot were all prepared in Tris buffer; (d) the free energy per contact of

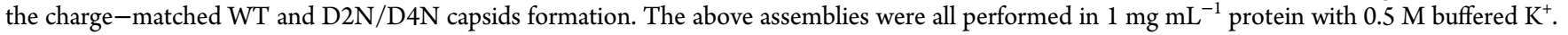
The error bar represents the standard deviation from three measurements.

capsid protein assembly is very similar to inorganic macroions represented by polyoxometalate (POM)-based inorganic clusters. Both capsid proteins and inorganic clusters are charged macromolecules with size ranging from 1 to $10 \mathrm{~nm}$ in diameter. They can no longer be treated as point charges because of their large sizes. To screen the intermolecular repulsion, metal ions of higher valences and lower hydrated radii associate more strongly with macroions, thus lowering CSC for supramolecular assembly. ${ }^{28}$ Therefore, multivalent ions play a more significant role in stabilizing capsids. To some virions, like southern bean mosaic virus, the deprivation of divalent ions would cause capsid dissociation. ${ }^{29-31}$

2.4. pH Effect on the Capsid Formation. The overall net charge of the HBV Cp149 dimer is $\mathrm{pH}$ dependent and can be estimated using Henderson-Hasselbalch equation. Charge numbers for both WT and D2N/D4N dimers within $\mathrm{pH}$ 6.6-9.6 were calculated (Table 1) using protein calculator 3.4 (http://protcalc.sourceforge.net). The effective charges on dimers can also be obtained through mobility measurement. The mobilities of WT dimer at $\mathrm{pH} 7.5$ (Tris buffer), $\mathrm{pH} 8.5$ (Tris buffer), and $\mathrm{pH} 9.6\left(\mathrm{NaHCO}_{3}\right.$ buffer) were -1.140 , -1.498 , and $-1.575 \mu \mathrm{m} \mathrm{cm} \mathrm{s}^{-1} \mathrm{~V}^{-1}$, respectively. The effective charges were calculated to be $-14.5,-17.6$, and -28.8 , which were close to theoretical results (Table S1, measurement and calculation details in the Supporting Information). As investigated in previous studies, ${ }^{3,18}$ the capsid formation became more difficult at a higher $\mathrm{pH}$ (higher protein charge density) (Figure 5a). Within a wide range of protein charge densities adjusted by $\mathrm{pH}$, both proteins assembled into capsids of the same sizes (Figure $5 \mathrm{~b}$ ), which means that the fidelity of capsid morphology was maintained by geometrical restriction through the hydrophobic contact.

A low protein charge density would enhance capsid formation, but it also decreased the solubility and even functionality of the capsids in solution. For example, when the overall charge of the mutant dimer was lowered to -8.4 (in HEPES buffer at $\mathrm{pH} 7$; dimer surface charge density was -0.23 charge $\mathrm{nm}^{-2}$ ), the addition of $0.5 \mathrm{M} \mathrm{KCl}$ induced a quick capsid formation followed by the extensive capsid aggregation (Figure S5), due to their limited solubility. Thus, capsids assembled from subunits of very low charges tended to easily aggregate or precipitate.

2.5. Equivalent Charge Density Led to Identical Capsid Assembly Process for WT and D2N/D4N. Under the same buffer condition and $\mathrm{pH}, \mathrm{D} 2 \mathrm{~N} / \mathrm{D} 4 \mathrm{~N}$ assembly was always more kinetically favored than WT due to its fewer 
charges (Figure 5a). An interesting question is if WT and mutant would behave the same when carrying the same number of charges. This can be answered by studying the capsid formation processes of WT and mutant at different $\mathrm{pHs}$ to match their charge densities. Protein concentration was maintained at $1.0 \mathrm{mg} \mathrm{mL}^{-1}$, and the protein structural stability under various $\mathrm{pHs}$ was confirmed in Figure S6. Assemblies of the $\mathrm{WT}$ and mutant were compared under conditions when they carry the same number of charges (Table 1). When $0.5 \mathrm{M}$ buffered $\mathrm{K}^{+}$was added into charge-matched solutions, as shown in Figure 5c, the kinetics of WT and mutant capsid formation followed a similar intensity growth path. This was also a strong indication that the different assembly behaviors between two proteins reported above were due to their charge difference.

In addition, a gap could be observed when the capsid formation tendency was plotted as a function of protein charge number. Using the intensity increment during the first hour as a measurement of assembly rate (Figures 5c and S3), the capsid assembly dramatically slowed down when WT Cp149 dimer bearing charges over -14.4 , which is exactly the charge number it carries at physiological $\mathrm{pH}$. This result suggested that the amino acid sequence was naturally designed to form assemblyoptimized dimer: the number of basic and acidic amino acid residues resulted in a net charge of -14.4 , which strikes a fine balance optimized for capsid formation without slowing down the proliferation speed or decreasing the capsid solubility.

The above samples (dimer charge numbers from -18.8 to -10.4) were given enough time to reach equilibrium and then tested by SEC to calculate both the capsid percentage and free energy per contact of the reactions as a function of charge numbers (Figures 5d and S4, and free energy calculation in the Supporting Information). When the charge density of capsid protein was lowered from -0.52 to -0.29 charge $\mathrm{nm}^{-2}$, both WT-0.5 $\mathrm{M} \mathrm{K}^{+}$and mutant-0.5 $\mathrm{M} \mathrm{K}^{+}$systems displayed a capsid percentage increased from 73 to $89 \%$. The corresponding free energy $\Delta G_{\text {contact }}$ varied from -3.32 to $-3.64 \mathrm{kcal}$ $\mathrm{mol}^{-1}$. Different capsid proteins reached the same thermodynamic equilibrium when they had the same charge density. The "assembly gap" in the first hour was a kinetic regulation step, which disappeared when the assembly process reached equilibrium.

2.6. Comparisons between the Capsid and Inorganic Blackberry Structure Formation. The spherical viral capsid structures share many similarities with the previously studied inorganic charged polyoxometalate (POM) macromolecules, which will self-assemble into hollow, spherical, single-layered, vesicular-like blackberry-type structure in solution. ${ }^{32}$ Assembled large icosahedral capsids and blackberry structures are still soluble and form homogeneous "real solutions", which distinguish them from colloidal particles. ${ }^{33}$ By changing macroion charge density, the assembly processes of both inorganic and protein macroions can be regulated correspondingly. The major driving force for the blackberry structure formation is the counterion-mediated electrostatic interaction, and the size of blackberry structure is sensitive to the macroion's charge density, which is controlled by the degree of deprotonation, solvent polarity, and/or ionic strength. ${ }^{33-36}$ Take $\left\{\mathrm{Mo}_{132}\right\}$ cluster $^{37}$ in water/acetone as an example, highly charged macroions $\left(-0.25 \mathrm{C} \mathrm{m}^{-2}\right)$ cannot self-assemble due to the strong repulsion between each other, whereas lowering charge density facilitates the blackberry structure formation. ${ }^{37}$ This is the same with capsid formation when the charge density of capsid protein is reduced by decreasing $\mathrm{pH}$ or adding salts. However, the size of blackberry structures can be reversibly tuned by changing the macroionic charges, which is not observed for HBV Cp149 capsid. In addition, the assembly rate for capsid protein is much faster than inorganic clusters. It takes hours or days for capsid formation to reach equilibrium, whereas weeks or even longer for blackberry structures. These differences can be attributed to the fact that the POM clusters do not have hydrophobic parts and the macroion-counterion interaction is dominant (the contributions of van der Waals attraction and hydrogen bonding are negligible), whereas capsid protein has special hydrophobic parts on its edges, which brings geometrical restriction to the capsid size. Because the hydrophobic attraction is a strong short-range noncovalent interaction, the capsid formation is much faster than blackberry formation. Also due to the existence of hydrophobic contact, dimers in capsid form direct dimer-dimer contacts which deprive them of free rotation, whereas POMs in blackberry structures are still single macroions with an interval distance of 0.4-0.7 nm. Therefore, once capsids are formed with preferred dimer orientation, it is difficult to change the capsid size even if conditions are varied, but the blackberry structures can adjust their sizes in response to conditions. Therefore, the protein-counterion interaction can affect the capsid formation kinetically and thermodynamically but not to alter capsid size.

\section{CONCLUSIONS}

In summary, a series of studies were conducted to determine the effect of HBV Cp149 protein charge density on its in vitro capsid formation. A mutant D2N/D4N dimer with exactly the same structural conformation as WT Cp149, but with four fewer negative charges at neutral $\mathrm{pH}$ was designed to probe the effect of charge. The kinetic and thermodynamic outcomes of capsid formation were identical for the WT and D2N/D4N dimers when they were charge matched, confirming that the capsid formation was controlled by the effective surface charge density (macroion-macroion repulsion) and the charge screening effect macroion-counterion interaction). A lower protein charge density favored capsid formation due to reduced electrostatic repulsion. The major impact of salts (ionic strength) was to screen this repulsion and balance the hydrophobic attraction, which was consequently important in regulating the speed of capsid formation and the amount of capsid at equilibrium. Experimental results also suggested that the charge number of WT $\mathrm{Cp} 149_{2}$ at physiological $\mathrm{pH}$ and ionic strength was well chosen by nature for an optimized balance between the efficient capsid generation and capsid stability. The way we treated capsid proteins as macroions to analyze HBV capsid formation could also be applied to many other viral capsids and self-assembled biological complexes. The fundamental understanding of electrostatic interaction in capsid formation, which was largely ignored before, could also lead to the development of new antiviral drugs.

\section{EXPERIMENTAL SECTION}

4.1. Protein Expression, Purification, and Characterization. For tag-free expression, the gene of WT HBV Cp149 was cloned into the expression vector pET24a, and the sequence was confirmed via DNA sequencing. The plasmid pET24A-Cp149 was then transformed into Escherichia coli strain BL21(DE3) strain for protein expression. A single colony was used to inoculate $10 \mathrm{~mL}$ of lysogeny broth (LB) media 
supplemented with $50 \mu \mathrm{g} \mathrm{mL} L^{-1}$ kanamycin (kan). The culture was incubated by shaking overnight and then diluted into $1 \mathrm{~L}$ fresh $\mathrm{LB} /$ kan media. When OD600 reached 0.8, isopropyl $\beta$-D1-thiogalactopyranoside was added to a final concentration of 2 $\mathrm{mM}$ to induce the expression of Cp149. Cells were incubated for another $5 \mathrm{~h}$ before collected by centrifugation at $7000 \mathrm{~g}$ for $10 \mathrm{~min}$. Purification was conducted following procedures as previously described. ${ }^{15}$ To construct a Cp149 mutant with a lower surface charge density, the negatively charged Asp2 and Asp4 were simultaneously replaced with Asn. Due to their close locations on the primary sequence, mutagenesis of these two sites was achieved via a single step of mutagenesis using the QuikChange Mutagenesis System (Agilent Genomics). The resultant mutant Cp149-D2N/D4N could be expressed to a similar level as the WT protein in E. coli, and the same purification procedure was conducted to extract the mutant (Figure S1B). Both WT and D2N/D4N mutant exist as a homodimer $\mathrm{Cp} 149_{2}$ in solution. Circular dichroism (CD) and fluorescence spectra of the WT and mutant Cp149 dimer protein were directly compared, and the overlapping of the two traces indicated that the Asp to Asn mutation at the N-terminus did not affect the overall conformation of the subunit (Figure S1D,E). Furthermore, purified D2N/D4N dimer showed a lower mobility under electronic field due to its four negative charges fewer on each Cp149 dimer (Figure S1C).

4.2. In Vitro Cp149 Dimer Assembly. The stock solutions of WT and mutant $\mathrm{Cp} 149_{2}$ were first dialyzed into the desired buffer at $4{ }^{\circ} \mathrm{C}$ overnight. Protein concentrations were determined through UV absorbance at $280 \mathrm{~nm}$ using an extinction coefficient of $29280 \mathrm{~cm}^{-1} \mathrm{M}^{-1}$ (for protein monomer). A $2.7 \mathrm{M} \mathrm{KCl}$ stock solution was prepared using the corresponding buffer and filtered before titrating into filtered protein solution. The assembly process was monitored using laser light scattering at $22^{\circ} \mathrm{C}$. The buffer systems used in this study were: $\mathrm{pH} 7.5$ HEPES (50 mM HEPES, $10 \mathrm{mM} \beta$ mercaptoethanol (BME), $\mathrm{pH}$ adjusted by $\mathrm{NaOH}$ ); $\mathrm{pH} 9.6$ $\mathrm{NaHCO}_{3}(50 \mathrm{mM} \mathrm{NaHCO}, 10 \mathrm{mM}$ BME, $\mathrm{pH}$ adjusted by $\mathrm{NaOH}$ ); pH 6.6-9.2 Tris (50 mM Trizma, $10 \mathrm{mM} \mathrm{BME,} \mathrm{pH}$ adjusted by $\mathrm{HCl}$ ).

4.3. Laser Light Scattering. A commercial Brookhaven Instrument laser light scattering spectrometer equipped with a solid-state laser operating at $532 \mathrm{~nm}$ was used for both static light scattering (SLS) and dynamic light scattering (DLS) measurements. The calibration intensity is $33.9 \mathrm{kcps}$, which is the scattered intensity of benzene at $90^{\circ}$. DLS measures the intensity-intensity time correlation function by means of a BI9000AT multichannel digital correlator. The field correlation function $\left|g^{(1)}(\tau)\right|$ was analyzed by the constrained regularized CONTIN $^{38}$ method to yield information on the distribution of the characteristic line width $\Gamma$. The normalized distribution function of the characteristic line width, $G(\Gamma)$, so obtained, can be used to determine an average apparent translational diffusion coefficient, $D_{\text {app }}=\Gamma / q^{2}$, where $q$ is the scattering factor. The hydrodynamic radius $R_{\mathrm{h}}$ is related to $D$ via the Stokes-Einstein equation: $R_{\mathrm{h}}=k T /(6 \pi \eta D)$ where $k$ is the Boltzmann constant and $\eta$ the viscosity of the solvent at temperature T. From DLS measurements, the particle-size distribution in solution is obtained from a plot of $\Gamma G(\Gamma)$ vs $R_{\mathrm{h}}$.

4.4. Transmission Electron Microscope (TEM). The overall structure of assembled Cp149 capsids was characterized using a JEOL-1230 electron microscope with an accelerating voltage of $120 \mathrm{kV}$. Samples for the TEM analysis were prepared by the standard negative staining method. A droplet of $8 \mu \mathrm{L}$ sample solution was placed onto a carbon film-coated copper grid (Ted Pella, Inc.), incubated for $90 \mathrm{~s}$ and then washed with water. The sample was stained using $1 \%$ uranyl acetate for $90 \mathrm{~s}$. The excess staining solution was removed, and the copper grid was left dry overnight prior to taking TEM images.

4.5. Size Exclusion Chromatography (SEC). SEC was performed using a $0.5 \mathrm{~cm}$ width Econo column packed with Sephacryl S-300 HR medium. The column was pre-equilibrated with $50 \mathrm{mM}$ HEPES or $50 \mathrm{mM}$ Tris buffer as used for the Cp $149_{2}$ assembly reaction plus $150 \mathrm{mM} \mathrm{KCl}$ to prevent capsids from disassembly during separation. $80 \mu \mathrm{L}$ of assembly solution was injected onto the column under a mild pressure of $3 \mathrm{psi}$, and the peaks of capsids and dimers were determined by UV absorbance at $280 \mathrm{~nm}$ via a Hewlett Packard Variable Wavelength Detector. Baseline was corrected and subtracted using Origin, and the integrated peak areas were used to calculate the capsid and dimer concentrations.

\section{ASSOCIATED CONTENT}

\section{Supporting Information}

The Supporting Information is available free of charge on the ACS Publications website at DOI: 10.1021/acsomega.8b00021.

Experimental details include protein preparation, circular dichroism and fluorescence characterization, gel electrophoresis, surface charge measurement, self-assembly free energy calculation, and Figures S1-S6 (PDF)

\section{AUTHOR INFORMATION}

\section{Corresponding Authors}

*E-mail: Yinan.Wei@uky.edu (Y.W.).

*E-mail: tliu@uakron.edu (T.L.).

ORCID $\odot$

Xinyu Sun: 0000-0003-4353-1832

Panchao Yin: 0000-0003-2902-8376

Jie Zheng: 0000-0003-1547-3612

Yinan Wei: 0000-0002-9936-7149

Tianbo Liu: 0000-0002-8181-1790

\section{Present Addresses}

$\nabla$ Department of Biological and Environmental Engineering, Cornell University, Ithaca, New York 14853, United States (Y.G.).

${ }^{\#}$ South China Advanced Institute for Soft Matter Science and Technology, South China University of Technology, Guangzhou 510640, P. R. China (P.Y.).

${ }^{\perp}$ Center for Pharmaceutical Research and Innovation College of Pharmacy, University of Kentucky, Lexington, Kentucky 40536, United States (Z.W.).

"Molecular Foundry, Lawrence Berkeley National Laboratory, Berkeley, California 94720, United States (D.L.).

\section{Notes}

The authors declare no competing financial interest.

\section{ACKNOWLEDGMENTS}

T.L. acknowledges support from NSF (CHE1607138) and The University of Akron. We also acknowledge Ashwin Sancheti and Krutika Invally from Dr. Lu-Kwang Ju's group from the Department of Chemical and Biomolecular Engineering, The University of Akron, for their help in the SEC measurements. 


\section{REFERENCES}

(1) Carter, J.; Saunders, V. A. Transcription, Translation, and Transport. Virology: Principles and Applications; John Wiley \& Sons, 2007.

(2) Harrison, S. C. Principles of Virus. Fields' Virology; Lippincott Williams \& Wilkins, 2007; Vol. 1, p 59.

(3) Speir, J. A.; Munshi, S.; Wang, G.; Baker, T. S.; Johnson, J. E. Structures of the native and swollen forms of cowpea chlorotic mottle virus determined by X-ray crystallography and cryo-electron microscopy. Structure 1995, 3, 63-78.

(4) Hagan, M. F.; Chandler, D. Dynamic pathways for viral capsid assembly. Biophys. J. 2006, 91, 42-54.

(5) Gelbart, W. M.; Knobler, C. M. Pressurized viruses. Science 2009, $323,1682-1683$.

(6) Garmann, R. F.; Comas-Garcia, M.; Gopal, A.; Knobler, C. M.; Gelbart, W. M. The assembly pathway of an icosahedral singlestranded RNA virus depends on the strength of inter-subunit attractions. J. Mol. Biol. 2014, 426, 1050-1060.

(7) Zlotnick, A.; Ceres, P.; Singh, S.; Johnson, J. M. A small molecule inhibits and misdirects assembly of hepatitis B virus capsids. J. Virol. 2002, 76, 4848-4854.

(8) De Clercq, E. Antiviral drugs in current clinical use. J. Clin. Virol. 2004, 30, 115-133.

(9) Stray, S. J.; Bourne, C. R.; Punna, S.; Lewis, W. G.; Finn, M. G.; Zlotnick, A. A heteroaryldihydropyrimidine activates and can misdirect hepatitis B virus capsid assembly. Proc. Natl. Acad. Sci. U.S.A. 2005, 102, 8138-8143.

(10) Stray, S. J.; Zlotnick, A. BAY 41-4109 has multiple effects on Hepatitis B virus capsid assembly. J. Mol. Recognit. 2006, 19, 542-548. (11) Katen, S. P.; Tan, Z.; Chirapu, S. R.; Finn, M. G.; Zlotnick, A. Assembly-directed antivirals differentially bind quasiequivalent pockets to modify hepatitis B virus capsid tertiary and quaternary structure. Structure 2013, 21, 1406-1416.

(12) Kang, L.; Pan, J.; Wu, J.; Hu, J.; Sun, Q.; Tang, J. Anti-HBV drugs: progress, unmet needs, and new hope. Viruses 2015, 7, 49604977.

(13) Zhang, L.; Liu, C.; Xiao, Y.; Chen, X. Oxethazaine inhibits hepatitis B virus capsid assembly by blocking the cytosolic calciumsignalling pathway. J. Gen. Virol. 2016, 97, 1198-1209.

(14) Wingfield, P. T.; Stahl, S. J.; Williams, R. W.; Steven, A. C. Hepatitis core antigen produced in Escherichia coli: subunit composition, conformation analysis, and in vitro capsid assembly. Biochemistry 1995, 34, 4919-4932.

(15) Zlotnick, A.; Cheng, N.; Conway, J.; Booy, F.; Steven, A.; Stahl, S.; Wingfield, P. Dimorphism of hepatitis B virus capsids is strongly influenced by the C-terminus of the capsid protein. Biochemistry 1996, $35,7412-7421$.

(16) Stray, S. J.; Ceres, P.; Zlotnick, A. Zinc ions trigger conformational change and oligomerization of hepatitis B virus capsid protein. Biochemistry 2004, 43, 9989-9998.

(17) Choi, Y.; Park, S. G.; Yoo, J.-h.; Jung, G. Calcium ions affect the hepatitis B virus core assembly. Virology 2005, 332, 454-463.

(18) Zlotnick, A.; Johnson, J. M.; Wingfield, P. W.; Stahl, S. J.; Endres, D. A theoretical model successfully identifies features of hepatitis B virus capsid assembly. Biochemistry 1999, 38, 1464414652.

(19) Ceres, P.; Zlotnick, A. Weak protein-protein interactions are sufficient to drive assembly of hepatitis B virus capsids. Biochemistry 2002, 41, 11525-11531.

(20) Lavelle, L.; Gingery, M.; Phillips, M.; Gelbart, W.; Knobler, C.; Cadena-Nava, R.; Vega-Acosta, J.; Pinedo-Torres, L.; Ruiz-Garcia, J. Phase diagram of self-assembled viral capsid protein polymorphs. J. Phys. Chem. B 2009, 113, 3813-3819.

(21) Bourne, C. R.; Katen, S. P.; Fultz, M. J.; Packianathan, C.; Zlotnick, A. A mutant hepatitis B virus core protein mimics inhibitors of icosahedral capsid self-assembly. Biochemistry 2009, 48, 1736.

(22) Tan, Z.; Pionek, K.; Unchwaniwala, N.; Maguire, M. L.; Loeb, D. D.; Zlotnick, A. The interface between hepatitis B virus capsid proteins affects self-assembly, pregenomic RNA packaging, and reverse transcription. J. Virol. 2015, 89, 3275-3284.

(23) Kegel, W. K.; van der Schoot, P. Competing hydrophobic and screened-Coulomb interactions in hepatitis B virus capsid assembly. Biophys. J. 2004, 86, 3905-3913.

(24) Siber, A.; Podgornik, R. Role of electrostatic interactions in the assembly of empty spherical viral capsids. Phys. Rev. E 2007, 76, No. 061906.

(25) Ceres, P.; Stray, S. J.; Zlotnick, A. Hepatitis B virus capsid assembly is enhanced by naturally occurring mutation F97L. J. Virol. 2004, 78, 9538-9543.

(26) Hiemenz, P. C.; Rajagopalan, R. Principles of Colloid and Surface Chemistry; CRC Press, 1997.

(27) Crowther, R. A.; Kiselev, N. A.; Böttcher, B.; Berriman, J. A.; Borisova, G. P.; Ose, V.; Pumpens, P. Three-dimensional structure of hepatitis $\mathrm{B}$ virus core particles determined by electron cryomicroscopy. Cell 1994, 77, 943-950.

(28) Pigga, J. M.; Teprovich, J. A.; Flowers, R. A.; Antonio, M. R.; Liu, T. Selective Monovalent Cation Association and Exchange around Keplerate Polyoxometalate Macroanions in Dilute Aqueous Solutions. Langmuir 2010, 26, 9449-9456.

(29) Hsu, C. H.; Sehgal, O. P.; Pickett, E. Stabilizing effect of divalent metal ions on virions of southern bean mosaic virus. Virology 1976, 69, $587-595$.

(30) Sorger, P. K.; Stockley, P.; Harrison, S. Structure and assembly of turnip crinkle virus: II. Mechanism of reassembly in vitro. J. Mol. Biol. 1986, 191, 639-658.

(31) Wells, J. M.; Sisler, H. D. The effect of EDTA and $\mathrm{Mg}^{2+}$ on the infectivity and structure of southern bean mosaic virus. Virology 1969, 37, 227-236.

(32) Liu, T.; Diemann, E.; Li, H.; Dress, A. W.; Müller, A. Selfassembly in aqueous solution of wheel-shaped $\mathrm{Mo}_{154}$ oxide clusters into vesicles. Nature 2003, 426, 59-62.

(33) Liu, T. Hydrophilic Macroionic Solutions: What Happens When Soluble Ions Reach the Size of Nanometer Scale? Langmuir 2010, 26, 9202-9213.

(34) Yin, P.; Li, D.; Liu, T. Solution behaviors and self-assembly of polyoxometalates as models of macroions and amphiphilic polyoxometalate-organic hybrids as novel surfactants. Chem. Soc. Rev. 2012, $41,7368-7383$.

(35) Eghtesadi, S. A.; Haso, F.; Kashfipour, M. A.; Lillard, R. S.; Liu, T. Supramolecular assembly of poly (propyleneimine) dendrimers driven by simple monovalent counterions. Chem. - Eur. J. 2015, 21, 18623-18630.

(36) Gao, Y.; Eghtesadi, S.; Liu, T. Chapter Two-Supramolecular Structures Formation of Polyoxometalates in Solution Driven by Counterion-Macroion Interaction. Adv. Inorg. Chem. 2017, 69, 29-65.

(37) Kistler, M. L.; Bhatt, A.; Liu, G.; Casa, D.; Liu, T. A Complete Macroion-"Blackberry" Assembly-Macroion Transition with Continuously Adjustable Assembly Sizes in $\{$ Mo132\} Water/Acetone Systems. J. Am. Chem. Soc. 2007, 129, 6453-6460.

(38) Provencher, S. W. CONTIN: a general purpose constrained regularization program for inverting noisy linear algebraic and integral equations. Comput. Phys. Commun. 1982, 27, 229-242. 